\title{
Erratum to: Analysis of Drug Distribution from a Simulated Drug-Eluting Stent Strut Using an In Vitro Framework
}

\author{
Caroline C. O’Brien, ${ }^{1}$ Charles H. Finch, ${ }^{1}$ Tracie J. Barber,${ }^{2}$ Penny Martens, ${ }^{1}$ and Anne Simmons ${ }^{2}$ \\ ${ }^{1}$ Graduate School of Biomedical Engineering, University of New South Wales, Sydney, NSW, Australia; and ${ }^{2}$ School of \\ Mechanical and Manufacturing Engineering, University of New South Wales, Sydney, NSW, Australia
}

\section{Erratum to: Annals of Biomedical Engineering} DOI: 10.1007/s10439-012-0604-6

1. In Materials and Methods, In Vitro Preparation, the glycerine/water solution is incorrectly described as $40 / 60 \mathrm{wt} \%$, when it should be $40 / 60$ vol. $\%$. The text should read: The working fluid consisted of a glycerine and water mixture $(40 / 60$ vol. $\%)$ with $0.01 \%$ surfactant, with the latter determined to be sufficiently small so as not to significantly alter fluid properties.
2. In Materials and Methods, In Vitro Preparation, the value of the kinematic viscosity was incorrectly recorded as $3.99 \mathrm{~cm}^{2} \mathrm{~s}^{-1}$, when it was in fact $0.0399 \mathrm{~cm}^{2} \mathrm{~s}^{-1}$. The sentence should read: The mixture provided a transparent working fluid with similar properties to that of blood, including density of $1101.4 \mathrm{~kg} \mathrm{~m}^{-3}$ and kinematic viscosity of $0.0399 \mathrm{~cm}^{2} \mathrm{~s}^{-1}$ at the experimental temperature of $23 \pm 0.2{ }^{\circ} \mathrm{C}$.
Address correspondence to Anne Simmons, School of Mechanical and Manufacturing Engineering, University of New South Wales, Sydney, NSW, Australia. Electronic mail: a.simmons@unsw.edu.au

The online version of the original article can be found under doi: 10.1007/s10439-012-0604-6. 